(2) Open Access Full Text Article

REVIEW

\title{
An update on the management of peripheral T-cell lymphoma and emerging treatment options
}

This article was published in the following Dove Press journal:

Journal of Blood Medicine

10 September 2011

Number of times this article has been viewed

\author{
Adrienne A Phillips' \\ Colette Owens ${ }^{2}$ \\ Sangmin Lee' \\ Govind Bhagat ${ }^{3}$ \\ 'Division of Medical Oncology, \\ Department of Medicine, ${ }^{2}$ Division \\ of General Medicine, Department of \\ Medicine, ${ }^{3}$ Department of Pathology \\ and Cell Biology, Columbia University \\ Medical Center and New York \\ Presbyterian Hospital, Columbia \\ University, New York, NY, USA
}

\begin{abstract}
Peripheral T-cell lymphomas (PTCLs) comprise a rare and heterogeneous subset of non-Hodgkin's lymphomas (NHLs) that arise from post-thymic T-cells or natural killer (NK)cells at nodal or extranodal sites. Worldwide, PTCLs represent approximately $12 \%$ of all NHLs and the 2008 World Health Organization (WHO) classification includes over 20 biologically and clinically distinct T/NK-cell neoplasms that differ significantly in presentation, pathology, and response to therapy. Because of the rarity and heterogeneity of these diseases, large clinical trials have not been conducted and optimal therapy is not well defined. Most subtypes are treated with similar combination chemotherapy regimens as used for aggressive B-cell NHL, but with poorer outcomes. New treatment combinations and novel agents are currently being explored for PTCLs and this review highlights a number of options that appear promising.
\end{abstract}

Keywords: treatment, non-Hodgkin's lymphoma, novel therapy, natural-killer cells

\section{Introduction}

Peripheral T-cell lymphomas (PTCLs) are a subset of non-Hodgkin's lymphomas (NHLs) that arise from lymphocytes at the post-thymic stage of maturation, which display T-cell or natural killer (NK)-cell immunophenotypes. In the broadest sense, any mature T-cell NHL is considered a peripheral T-cell lymphoma, with the exception of lymphoblastic lymphoma (ie, the lymphoma counterpart of T-cell acute lymphoblastic leukemia). Advances in the understanding of T-cell biology and molecular alterations of T-NHL over the past decade have led to a refinement of the World Health Organization (WHO) classification system. Currently, the category PTCL comprises over 20 biologically and clinically distinct entities based on their epidemiology, clinical features, morphology, immunophenotype, and underlying genetic lesions (Table 1). ${ }^{1,2}$

Worldwide, PTCLs represent approximately $12 \%$ of all NHLs. ${ }^{3}$ Ethnic and geographic variations account for differences in prevalence, however, with rates ranging from $24 \%$ in Asia to $4 \%$ in North America. The incidence in the USA increased $7.9 \%$ annually between 1992 and $2005 .{ }^{4}$ The reason behind the geographic variation is not entirely clear but may be related to exposure or genetic susceptibility to pathogenic agents in Asian countries, notably human T-cell lymphotropic virus type I (HTLV-1) infection and adult T-cell leukemia/lymphoma (ATLL) and Epstein-Barr virus (EBV) infection and NK/T-cell lymphoma (NKTCL). ${ }^{5}$ A recent international collaborative study ${ }^{6}$ also suggests geographic variation for other PTCL subtypes (Table 2). The International T-cell Lymphoma Project (ITLP) is an impressive effort involving over 22 centers worldwide that has collected data on 1314 cases of PTCL over 12 years. ${ }^{6}$ Overall, the most common PTCL subtypes identified were peripheral T-cell lymphoma, not otherwise 
Table I Mature T- and NK-cell neoplasms: the World Health Organization (WHO) classification 200I and 2008,2

\begin{tabular}{|c|c|c|}
\hline & WHO classification 200 I & WHO classification 2008 \\
\hline \multirow[t]{6}{*}{ Leukemic } & T-PLL & T-PLL \\
\hline & T-LGLL & T-LGL \\
\hline & Aggressive NK-cell leukemia & Chronic LPDs of NK-cells ${ }^{\mathrm{b}}$ \\
\hline & ATLL (HTLV-I+) & Aggressive NK-cell leukemia \\
\hline & & ATLL (HTLV-I+) \\
\hline & & Systemic EBV-positive T-cell LPDs of childhood \\
\hline \multirow[t]{4}{*}{ Nodal } & AITL & AITL \\
\hline & ALCL, systemic type & ALCL, ALK-positive \\
\hline & PTCL-U & ALCL, ALK-negative ${ }^{c}$ \\
\hline & & PTCL-NOS \\
\hline \multirow[t]{4}{*}{ Extranodal } & Extranodal NK-/T-cell lymphoma, nasal type & Extranodal NK-/T-cell lymphoma, nasal type \\
\hline & Enteropathy-type T-cell lymphoma & Enteropathy-associated T-cell lymphoma \\
\hline & Hepatosplenic $\gamma \delta$ T-cell lymphoma & Hepatosplenic T-cell lymphoma \\
\hline & Subcutaneous panniculitis-like T-cell lymphoma & Subcutaneous panniculitis-like T-cell lymphoma \\
\hline \multirow[t]{7}{*}{ Cutaneous } & Mycosis fungoides & Mycosis fungoides \\
\hline & Sézary syndrome & Sézary syndrome \\
\hline & Primary cutaneous CD30+ T-cell LPD & Primary cutaneous CD30+ T-cell LPD \\
\hline & - ALCL, cutaneous type & - Primary cutaneous aggressive epidermotropic \\
\hline & - Lymphomatoid papulosis ${ }^{\mathrm{a}}$ & $\mathrm{CD} 8+\mathrm{TCL}^{\mathrm{c}}$ \\
\hline & Borderline lesions & - Primary cutaneous small/medium $\mathrm{CD} 4+\mathrm{TCL}^{\mathrm{c}}$ \\
\hline & & Primary cutaneous $\gamma \delta \mathrm{TCL}^{\mathrm{b}}$ \\
\hline Uncertain & Blastic NK-cell lymphoma & \\
\hline
\end{tabular}

Notes: a Not considered a neoplastic disorder; ${ }^{b}$ new distinct entity; ${ }^{c}$ provisional entity.

Abbreviations: T-PLL, T-cell prolymphocytic leukemia; T-LGLL, T-cell large granular lymphocytic leukemia; T-LGL, T-cell large granular lymphocytic leukemia; ATLL, adult T-cell leukemia/lymphoma; HTLV-I, human T lymphotropic virus, type I; LPD, lymphoproliferative disorder; PTCL, peripheral T-cell lymphoma; PTCL-U, peripheral T-cell lymphoma, unspecified; PTCL-NOS, peripheral T-cell lymphoma, not otherwise specified; ALCL, anaplastic large-cell lymphoma; ALK, anaplastic lymphoma kinase.

specified (PTCL-NOS) (25.9\%), angioimmunoblastic T-cell lymphoma (AITL) (18.5\%), natural killer/T-cell lymphoma NKTCL (10.4\%), and adult T-cell leukemia/lymphoma (ATLL) (9.6\%). With few exceptions, the course of most PTCL subtypes is aggressive and the clinical outcome is poor. The 5-year overall survival (OS) for the most common subtypes identified was $32 \%, 32 \%, 42 \%$, and $14 \%$, respectively. ${ }^{6}$

The optimal therapeutic strategy for most PTCL subtypes is unknown. A low overall incidence and prevalence of PTCLs combined with disease heterogeneity has made it challenging to conduct randomized or multi-institutional trials. Regimens for aggressive B-cell NHL are frequently used and, with the exception of anaplastic lymphoma kinase (ALK)-positive anaplastic large-cell lymphoma (ALCL) (which has an excellent outcome with anthracycline-based combination chemotherapy), other PTCLs have poor outcomes. ${ }^{6}$ The tendency for poor survival in PTCL suggests that the same regimens may not be equally efficacious in patients with aggressive B- and T-cell lymphomas. New combinations

Table 2 Major lymphoma subtypes by geographic region in the International T-cell lymphoma project ${ }^{6}$

\begin{tabular}{lllll}
\hline PTCL subtype & Overall (\%) & North America (\%) & Europe (\%) & Asia (\%) \\
\hline PTCL-NOS & 25.9 & 34.4 & 34.3 & 22.4 \\
AITL & 18.5 & 16.0 & 28.7 & 17.9 \\
ALCL, ALK+ & 6.6 & 16.0 & 6.4 & 3.2 \\
ALCL, ALK- & 5.5 & 7.8 & 9.4 & 2.6 \\
NKTCL & 10.4 & 5.1 & 4.3 & 22.4 \\
ATLL & 9.6 & 2.0 & 1.0 & 25 \\
Enteropathy-type TCL & 4.7 & 5.8 & 9.1 & 1.9 \\
Hepatosplenic TCL & 1.4 & 3.0 & 2.3 & 0.2 \\
Primary Cutaneous ALCL & 1.7 & 5.4 & 0.8 & 0.7 \\
SCPTCL & 0.9 & 1.3 & 0.5 & 1.3 \\
\hline
\end{tabular}

Abbreviations: PTCL-NOS, peripheral T-cell lymphoma, not otherwise specified; AITL, angioimmunoblastic T-cell lymphoma; ALCL, anaplastic large-cell lymphoma; ALK, anaplastic kinase; NKTCL, natural killer T-cell lymphoma; ATLL, adult T-cell leukemia/lymphoma; TCL, T-cell lymphoma; SCPTCL, subcutaneous panniculitis-like T-cell lymphoma+; PTCL, peripheral T-cell lymphoma.

Note: Adapted from Vose J, Armitage J, Weisenburger D. International T-Cell Lymphoma Project. International peripheral T-cell and natural killer/T-cell lymphoma study: pathology findings and clinical outcomes. J Clin Oncol. 2008;26(25):4I24-4130. Reprinted with permission. @ 2008 American Society of Clinical Oncology. All rights reserved. 
of therapy, dose-intensified therapies and novel agents are necessary. This review summarizes the main clinicopathologic features of the common PTCL subtypes and the current and emerging treatment options that are available. Some subtypes have unique pathophysiology that require treatment modifications and this will also be reviewed where applicable.

\section{PTCL-NOS}

PTCL-NOS is the most common subtype of PTCL, accounting for approximately $26 \%$ of cases worldwide. ${ }^{6}$ This "default" PTCL category includes all cases not readily classifiable into other specific T-cell entities of the WHO classification. Distinguishing PTCL-NOS from ALKnegative ALCL is challenging and the clinical relevance of distinguishing between these entities has been debated. ${ }^{7,8}$ Distinct, as well as shared, chromosomal alterations have been described between PTCL-NOS and ALK-negative ALCL, the latter including gains at chromosomes 1q and $3 p$ and losses at chromosome 6q. ${ }^{9}$ Abnormalities at some of these loci have also been confirmed by higher resolution genomic analysis. ${ }^{10}$ Alterations of the NF kappa B signaling pathway have been described in a subset of PTCL-NOS, and expression of platelet-derived growth factor receptor alpha has also been reported in some cases. ${ }^{11,12}$ Streubel et al documented a recurrent translocation $\mathrm{t}(5: 9)$ (q33:32) leading to the fusion of the inducible T-cell kinase gene located on chromosome 5 with the spleen tyrosine kinase gene located on chromosome 9 in $<20 \%$ of PTCL-NOS. ${ }^{13}$ These and other abnormalities suggest a role for alterations in constitutive activation of T-cell receptor signaling in disease pathogenesis and may pave the way for development of better diagnostic and prognostic markers. ${ }^{14}$

PTCL-NOS typically occurs in adults at the median age of 55-60 years, and a higher prevalence is seen in males. ${ }^{4,15}$ Patients frequently present with advanced disease and extranodal involvement is common despite previous classification as a "nodal" disease subtype. ${ }^{4,15}$ A prognostic index for T-cell lymphoma has been proposed, which incorporates the following factors: advanced age, poor performance status, elevated lactate dehydrogenase levels, and bone marrow involvement. ${ }^{16}$ In this model, 5-year OS ranged from $18 \%$ (with four factors) to $62 \%$ (with one factor). ${ }^{16}$ The treatment of PTCL-NOS is not well established and will be discussed further in this paper.

\section{AITL}

AITL, originally described as "angioimmunoblastic lymphadenopathy (AILD) with dysproteinemia," is the second most common PTCL subtype, accounting for about $18.5 \%$ of cases. ${ }^{6}$ It is thought to derive from a T-follicular helper cell, based on phenotypic and gene expression profile analysis. ${ }^{17}$ Most patients present in the sixth or seventh decade (median age 59-64 years) without any gender predilection. ${ }^{17}$ Originally thought to be a form of abnormal immune response, patients typically present with B-symptoms (fever, night sweats, unintentional weight loss), generalized lymphadenopathy, and advanced stage disease that may mimic an infectious process. ${ }^{17}$ Laboratory studies commonly reveal anemia, hypergammaglobulinemia, and an elevated lactate dehydrogenase, and a significant proportion of patients have circulating autoantibodies, which may manifest as a positive direct antiglobulin test, cold agglutinins, cryoglobulins, and circulating immune complexes. ${ }^{15,17}$ A number of autoimmune phenomena have been reported in association with AITL. ${ }^{15,17}$ The course of AITL is variable, with occasional spontaneous remissions in some but, overall, prognosis is poor.

The pathogenesis of AITL is poorly understood. Classical cytogenetic studies have identified a few recurrent chromosomal alterations in AITL, which include gains of chromosomes $3 \mathrm{q}, 5 \mathrm{q}$, and 21 , although the genes affected by these alterations are not known. ${ }^{9}$ High-resolution genomic analysis and whole genome or exome sequencing of these lymphomas might be more informative. Recent gene expression profile analysis of AITL has suggested a role of the tumor microenvironment in AITL pathogenesis. ${ }^{18}$ Underlying immune dysfunction has long been suspected, as has a role for viral infection, especially EBV and human herpesvirus 6, although specific viral factors or mediators influencing the course of disease are yet unknown. ${ }^{17}$

The best treatment approach for AITL is unknown and therapeutic strategies have ranged from assuming a "watch and wait" attitude to the use of single-agent steroids, cytotoxic drugs, or combination chemotherapy regimens. The use of steroids has been recommended in the elderly. However, when used as first-line therapy, the duration of response is shorter than with chemotherapy and, overall, combination chemotherapy appears to be superior to steroids alone. ${ }^{19}$ Combination regimens, including CHOP (cyclophosphamide, doxorubicin, vincristine, prednisone), CVP (cyclophosphamide, vincristine, prednisone), and VAP (vincristine, doxorubicin, and prednisolone), can produce complete remission rates of up to $50 \%$, but relapse rates remain high. ${ }^{19}$ At this time, no therapy has increased the long-term survival rate to more than $30 \% .{ }^{6}$ Other therapeutic approaches in AITL have targeted immune dysregulation; these include cyclosporine, low-dose methotrexate, interferon-alpha, thalidomide, rituximab, and alemtuzumab, but there is no consensus on whether any 
of these agents improve outcomes more than conventional therapy. ${ }^{19,20-24}$

Consolidation with high-dose therapy followed by autologous stem cell transplantation (ASCT) for patients in their first complete response (CR) or with chemosensitive relapse should be considered in suitable patients with AITL. The European Group for Blood and Marrow Transplantation retrospectively assessed 142 patients who received ASCT in differing situations (relapse, refractory, first CR) and, after a median follow-up of 31 months, OS was 67\% at 24 months and $59 \%$ at 48 months. The estimated 4-year progressionfree survival (PFS) rate was best for patients receiving their transplant in CR (56\% versus $30 \%$ in chemosensitive relapse and $23 \%$ in refractory disease). ${ }^{25}$ In young patients (median age 48), retrospective data on allogeneic transplantation are encouraging but patient cohorts are limited. ${ }^{26}$

\section{ALCL}

ALCL was originally described in 1985 by Stein et al as a lymphoma composed of large anaplastic lymphocytes that express CD30. ${ }^{27}$ Since then, there has been significant progress in further classifying ALCL based on the presence of the characteristic chromosomal translocation $\mathrm{t}(2 ; 5)$ (p23;q35), which results in the nucleophosmin (NPM)/ALK (NPM-ALK) fusion protein and causes constitutive activation of the ALK tyrosine kinase, leading to uncontrolled cell proliferation. ${ }^{28}$ An understanding of alterations in different signaling pathways affected by the translocation, especially the Janus kinase (JAK)/signal transducer and activator of transcription (STAT) (JAK-STAT) pathway that leads to constitutive activation of STAT3, the phosphatidylinositol 3-kinase (PI3-kinase)/protein kinase (AKT) pathway, CD30, Myc, phospholipase C- $\gamma$ (PLC $\gamma)$, and growth factor receptor-bound protein 2 (Grb2) (an adaptor protein) have been described. ${ }^{29}$ Translocations involving ALK and other partner genes have also been documented, but they only account for a minority of cases. ${ }^{29}$

NPM-ALK translocations are seen in $60 \%-85 \%$ of systemic ALCL with higher frequencies seen in the pediatric and young-adult age groups. ${ }^{28,30,31}$ Because of its unique clinicopathologic features, ALK-positive ALCL is considered a distinct entity, distinguished from ALK-negative ALCL in the WHO classification. ${ }^{1}$ ALK-positive patients have a median age of 34 years compared with a median age of 58 years for patients with ALK-negative ALCL, with no differences in gender or stage at presentation. ${ }^{31}$

ALK-positive ALCL is a chemosensitive malignancy with outcomes comparable to, or better than, International
Prognostic Index (IPI)-adjusted diffuse large B-cell lymphoma (DLBCL) following anthracycline-based combination chemotherapy. ${ }^{32}$ Trials reporting solely ALK-positive ALCL are few, but in one series, a CR rate of $77 \%$ was reported with OS of $71 \%$ at 10 years. ${ }^{33}$ Due to superior outcomes of adult ALK-positive ALCL with anthracyclinebased chemotherapy, transplant should only be considered at relapse. ALK-positive ALCL patients undergoing ASCT at relapse have a 67\%-100\% 3-year PFS and a 78\%-100\% 3-year OS. ${ }^{34,35}$ Prognosis for ALK-negative ALCL lies between ALK-positive ALCL and PTCL-NOS with a 5-year OS of $49 \%$ compared with $19 \%$ for PTCL-NOS. ${ }^{6}$

The fact that NPM-ALK plays a critical role in the development and pathogenesis of ALK+ ALCL has made this chimeric protein a therapeutic target in this disease. Crizotinib, an inhibitor of the ALK tyrosine kinase, is active in non-small-cell lung cancers expressing ALK. ${ }^{36}$ Two case reports indicate sensitivity of relapsed, advanced ALK-positive ALCLs to ALK inhibition. ${ }^{37}$ Immunotherapy targeting CD30 is another possible approach and will be discussed further.

\section{NKTCL}

NK cells are closely related to T cells and neoplasms derived from these cells are thus classified within the same group. Overall, NKTCLs represent $10.4 \%$ of all PTCL, however prevalence is much higher in Asian countries (22.4\%) compared with North America and Europe (4\%-5\%) (Table 2). ${ }^{6}$ NKTCL is associated with EBV and usually presents in men at the median age of $43 .{ }^{38}$ Though most cases present in the nasal region and associated structures, identical tumors can also occur in extranasal sites, such as the skin, soft tissue, gastrointestinal tract, and testis. Extranasal cases have more adverse clinical features and poorer survival, even with apparently localized disease (5-year OS, 9\% versus 42\%). ${ }^{6}$ As with other T-cell lymphomas, the pathogenesis of NKTCL remains poorly understood. A recurrent genetic alteration of chromosome $6 \mathrm{q}$ has been described and a potential tumor suppressor $H A C E 1$ has recently been mapped to this location, but the role of this gene in disease pathogenesis is currently not known. ${ }^{39}$

Therapy for NKTCL is not standardized; however, radiotherapy is an effective treatment for patients with limited disease. In a study of 64 patients with early stage NKTCL who received radiotherapy alone or chemoradiotherapy as first-line therapy, there was no difference in 5-year OS (57\% versus $62 \%, P=0.47) .{ }^{40}$ For patients with disseminated or relapsing disease, a Phase II study of L-asparaginase with 
methotrexate and dexamethasone revealed a $61 \% \mathrm{CR}$ rate and the main toxicities were hepatitis, cytopenias, and allergy. ${ }^{41}$

\section{ATLL}

ATLL is caused by the retrovirus human T-lymphotropic virus type I (HTLV-1), which is endemic in Japan, Central Africa, the Caribbean, Papua New Guinea, South America, and is present in regions of the USA where populations have immigrated. HTLV-1 affects 20 million individuals worldwide although $95 \%$ will likely remain asymptomatic carriers. The estimated lifetime risk of developing ATLL is $2 \%-6 \%$ among HTLV-1 carriers. ${ }^{42}$ ATLL is subdivided into four clinical subtypes: (1) acute (leukemic) (57\%), (2) lymphoma (19\%), (3) chronic (19\%), and (4) smoldering (5\%). ${ }^{43}$ The main clinical manifestations of ATLL include lymphadenopathy, hepatosplenomegaly, skin lesions, osteolytic lesions, and hypercalcemia depending on the subtype. Prognoses for the acute and lymphoma subtypes are the poorest with a median survival of only 6.2 and 10.2 months, respectively. ${ }^{43}$

Disease pathogenesis involves interactions between viral and host factors. A variety of viral proteins with transforming activity have been described, but most work has focused on the Tax protein, which is thought to activate the NF kappa B transcription factor complex. ${ }^{44}$ Recent work has suggested that c-Rel and IRF-4 expression is associated with antiviral resistance of ATLL. ${ }^{45}$ Array-based comparative genomic hybridization studies have also highlighted differences in chromosomal alterations between the acute and lymphoma subtypes and have provided limited information regarding the genes targeted by these alterations. ${ }^{46}$ Understanding molecular pathways affected by the viral factors and tumorassociated genetic abnormalities might allow for targeted and effective therapeutic approaches.

Chemotherapy has had limited success in treatment of ATLL. The Japan Clinical Oncology Group has performed six prospective clinical trials of conventional chemotherapy. ${ }^{47}$ Most recently, the results of a Phase III study suggest that, at the expense of higher toxicities, the vincristine, cyclophosphamide, doxorubicin, and prednisone (VCAP); doxorubicin, ranimustine, and prednisone (AMP); and vindesine, etoposide, carboplatin, and prednisone (VECP) regimens are superior to biweekly CHOP in newly diagnosed, acute, lymphoma, or unfavorable chronic types of ATLL. The rate of CR was higher in the VCAP-AMP-VECP arm than the biweekly CHOP arm (40\% versus $25 \%, P=0.020)$. OS at 3 years was $24 \%$ in the VCAP-AMP-VECP arm and $13 \%$ in the CHOP $\operatorname{arm}(P=0.085){ }^{48}$
Several studies have shown promising use of zidovudine (AZT) and interferon alpha (IFN- $\alpha$ ). Combination of AZT and IFN- $\alpha$ in acute leukemia or lymphomatous forms of ATLL have produced CR rates ranging from $26 \%-58 \%$, median OS ranging from 3-18 months, and median OS for responders ranging from 13-28 months. ${ }^{49-51} \mathrm{~A}$ recent meta-analysis reported a 5-year OS rate of $46 \%$ for patients receiving firstline antiviral treatment and concluded that AZT and IFN- $\alpha$ should be the standard first-line therapy of leukemic subtypes of ATLL. ${ }^{52}$ Monoclonal antibodies (anti-CD25, anti-CD4, anti-CD52, anti-CCR4, antitransferrin receptor) and novel agents (arsenic trioxide, bortezomib) have been tested in small numbers of patients and clinical trials are needed to better define the roles of these agents. ${ }^{47}$ There is little long-term benefit to autologous stem cell transplantation, although prolonged disease-free survival has been reported for allogeneic transplant in retrospective analyses..$^{53,54}$

\section{Rare peripheral T-cell lymphoma subtypes}

Enteropathy associated T-cell lymphoma (EATL) accounts for less than $5 \%$ of PTCL and has been recognized as having a poor prognosis. ${ }^{6}$ The disease is usually associated with celiac disease and the HLA DQ2 haplotype, and is more commonly seen in Northern Europe due to a higher incidence of celiac disease. ${ }^{6,55}$ Typically, patients are older men who present with diarrhea and abdominal pain. Like other subtypes of PTCL, the outcome of patients with this disease receiving anthracycline-based chemotherapy has been poor, with most patients relapsing or dying of their disease. Treatment is complicated by poor nutrition and a significant risk of bowel perforation. ${ }^{55}$ Small series of individuals undergoing regimens involving ASCT have shown some benefit. ${ }^{56}$ Cladribine therapy has recently been proposed for treating refractory celiac disease type II, which is considered a precursor of EATL, with good histologic and clinical response, though long-term studies are warranted. ${ }^{57}$

Hepatosplenic T-cell lymphoma is another uncommon T-cell lymphoma mainly seen in young males with a median age of 35 years. The disease may be seen following organ transplantation or be related to other causes of immunosuppression and is slightly more common in North America and Europe than Asia. ${ }^{6,58}$

Subcutaneous panniculitis-like T-cell lymphoma is one of the rarest subtypes of T-cell lymphoma that does not appear to have any geographic variation. ${ }^{6}$ It can be seen in any age, but the median age is 36 years, with a male to female ratio of $2: 1$. 
Optimal therapies for the aforementioned entities remain undefined at the time of writing.

\section{Emerging treatment options for PTCL}

Until the rituximab era, treatment for patients with PTCL was approached in the same way as that for B-cell NHL. Outside of a clinical trial, CHOP or CHOP-like chemotherapy regimens (eg, EPOCH [etoposide, prednisone, vincristine, cyclophosphamide, doxorubicin] or hyperCVAD [hyperfractionated cyclophosphamide, vincristine, doxorubicin and decadron] alternating with high-dose methotrexate and cytarabine) are considered reasonable options. ${ }^{59}$ The large Intergroup trial, which established that $\mathrm{CHOP}$ was equally efficacious and less toxic than other chemotherapy combinations in aggressive NHLs, was conducted in an era when routine immunophenotyping to distinguish $\mathrm{B}$ - and $\mathrm{T}$-cell lineage was not performed. ${ }^{60}$ Unfortunately, with the notable exception of ALK-positive ALCL, outcomes with CHOP in PTCL have been poor. ${ }^{6}$ But, despite these suboptimal results, few studies have compared CHOP with other regimens in the initial treatment of PTCL. Furthermore, the role of anthracyclines, particularly in the treatment of PTCL-NOS, has been questioned. ${ }^{6}$

The German High-Grade Non-Hodgkin's Lymphoma Group evaluated the outcome of 289 patients with ALKpositive ALCL, ALK-negative ALCL, PTCL-unclassified (now PTCL-NOS), and AITL treated on their protocols. ${ }^{61}$ Treatment consisted of 6-8 cycles of CHOP or etoposide plus CHOP (CHOEP). Three-year event-free survival (EFS) and OS was $75.8 \%$ and $89.8 \%$ (ALK-positive ALCL), $50.0 \%$ and $67.5 \%$ (AITL), $45.7 \%$ and $62.1 \%$ (ALK-negative ALCL), and $41.1 \%$ and $53.9 \%$ (PTCL-U). For younger patients, the addition of etoposide improved response rates. The difference in EFS for younger patients and ALK-positive ALCL treated with CHOP or CHOEP was impressive (3-year EFS for CHOEP patients was $91.2 \%$ versus $57.1 \%$ for patients treated with CHOP, $P=0.12$ ), and no statistically significant difference was seen in the remaining patients when ALKpositive ALCL was excluded (3-year EFS for CHOEP patients $60.7 \%$ versus $48.3 \%$ for patients treated with $\mathrm{CHOP}$, $P=0.57$ ). Although this difference was not statistically significant, the authors concluded that CHOEP should be administered as first-line therapy to younger patients with T-cell lymphoma.

The Groupe Ouest-Est D'etudes Des Leucémies Aigües Et Autres Maladies Du Sang (GOELAMS) tested alternating VIP (etoposide, ifosfamide, cisplatin)/ABVD (adriamycin, bleomycin, vinblastine, dacarbazine) for a total of six cycles against CHOP for eight cycles in treatment-naïve patients with PTCLs and found there was no difference in EFS and OS between these regimens. ${ }^{62} \mathrm{~A}$ Korean group evaluated a CHOP-like regimen (CEOP-B [cyclophostamide, epirubicin, vincristine, prednisone, bleomycin]), with epirubicin substituted for doxorubicin and the addition of bleomycin, in patients with T-cell lymphomas (one patient with lymphoblastic lymphoma) with primarily low-risk disease (38\% IPI 0 or 1) and reported a 5-year OS of $49 \%$; however, the estimated 5-year PFS was only $30 \% .{ }^{63}$ Table 3 highlights other frontline therapeutic studies. However, none of these report outcomes that are statistically significantly improved over $\mathrm{CHOP}$ at this time. ${ }^{62-68}$

\section{Stem cell transplantation}

Poor results with conventional chemotherapy have led to the exploration of high-dose chemotherapy supported by autologous or allogeneic stem cell transplantation. A number of uncontrolled prospective and retrospective studies suggest that upfront high-dose chemotherapy with ASCT as consolidation in patients who attain CR following first-line therapy may result in superior disease control and improved OS. ${ }^{69}$ In a retrospective study of 115 patients with PTCL, the Grupo Español de Linfomas y Trasplantes de Médula Ósea (GEL-TAMO) showed a 5-year OS rate of $80 \%$ was achieved in 37 patients who were transplanted in first CR compared with $45 \%$ in those treated in a salvage setting. ${ }^{70}$ Reimer et al conducted the largest prospective study of upfront ASCT for patients with PTCL. ${ }^{71}$ Of 83 patients enrolled, 55 underwent ASCT; the estimated 3-year OS rate for these patients ASCT was $71 \%$ compared with $11 \%$ for those that did not. About $33 \%$ of patients did not undergo ASCT for a variety of reasons, including disease progression (in 29\%). ${ }^{71}$

The role of allogeneic transplantation has also been preliminarily investigated. In a prospective study of 17 patients with relapsed or refractory PTCL undergoing salvage chemotherapy and reduced-intensity allogeneic transplantation, at a median follow-up of 28 months, 14/17 patients were alive. The estimated 3-year OS and PFS were $81 \%$ and $64 \%$, respectively, suggesting a possible graftversus-lymphoma effect. ${ }^{72}$ The therapy-related mortality was $6 \%$. In a retrospective study of 77 patients with PTCL who underwent allogeneic stem cell transplantation, the 5-year OS and EFS rates were $57 \%$ and 53\%, respectively. ${ }^{73}$ The 5-year OS for chemoresistant patients was $29 \%$ and the treatment-related mortality was $33 \%$. The German 
Table 3 Selected studies of first-line therapies in PTCL

\begin{tabular}{|c|c|c|c|c|}
\hline Study & Agent & Patient number (n) & ORR & Notable toxicities \\
\hline $\mathrm{Kim}^{64}$ & CHOEP + gemcitabine & 26 & $77 \%$ & Grade 4 neutropenia (54\%) \\
\hline Sung ${ }^{63}$ & CEOP-B & 52 & $63.5 \%$ & Neutropenia \\
\hline Gallamini 66 & Alemtuzumab + CHOP & 24 & $75 \%$ & $\begin{array}{l}\text { Grade } 4 \text { neutropenia and CMV reactivation } \\
\text { Other major infections-JCV, pulmonary } \\
\text { invasive aspergillosis, staph } \\
\text { sepsis and pneumonia }\end{array}$ \\
\hline $\mathrm{Kim}^{65}$ & Alemtuzumab + CHOP & 20 & $80 \%$ & $\begin{array}{l}90 \% \text { grade } 4 \text { neutropenia } \\
55 \% \text { febrile neutropenia } \\
25 \% \text { CMV reactivation* }\end{array}$ \\
\hline Simon ${ }^{62}$ & VIP-rABVD vs CHOP 21 & $\begin{array}{l}88 \text { patients } \\
\text { randomized }\end{array}$ & $\begin{array}{l}62 \% \text {, no difference } \\
\text { between two arms }\end{array}$ & $\begin{array}{l}\text { Hematologic toxicity, transfusion requirement, } \\
\text { and hospitalizations higher in VIP-rABVD arm }\end{array}$ \\
\hline Takamatsu $^{67}$ & THP-COP & 53 & $66 \%$ & Grade $3 / 4$ cytopenias \\
\hline Kluin-Nelemans ${ }^{68}$ & $\begin{array}{l}\text { Alemtuzumab }+ \text { CHOP } \\
\text { (intensified) }\end{array}$ & 20 & $90 \%$ & $\begin{array}{l}\text { Neutropenic fever, CMV reactivation/disease, } \\
\text { EBV-related lymphoma }\end{array}$ \\
\hline
\end{tabular}

Note: *Study closed due to adverse events.

Abbreviations: ORR, overall response rate; CHOP, cyclophosphamide, doxorubicin, vincristine, prednisone; CHOEP, cyclophosphamide, doxorubicin, vincristine, prednisone, etoposide; CEOP-B, modified cyclophosphamide, epirubicin, vincristine, prednisone; VIP-rABVD, alternative therapeutic schedule including etoposide, ifosfamide, cisplatin alternating with doxorubicin, bleomycin, vinblastine, dacarbazine; THP-COP, pirarubicin, cyclophosphamide, vincristine, prednisolone; CMV, cytomegalovirus; JC, John Cunningham virus; EBV, Epstein-Barr Virus; PTCL, peripheral T-cell lymphoma.

High-Grade Non-Hodgkin's Lymphoma Study Group is initiating a randomized multicenter trial comparing upfront ASCT with allogeneic stem cell transplantation.

\section{Novel agents}

A significant effort has been made to identify novel targets for the treatment of PTCL and a number of targeted therapies are being investigated in early clinical trials (Tables 3 and 4). These agents include antimetabolites, histone deacetylase (HDAC) inhibitors, and immunotherapies, as well as others.

\section{Antimetabolites}

Pralatrexate (PDX) is an antifolate agent and one of two drugs approved by the US Food and Drug Administration (FDA) for use in relapsed or refractory PTCL. PDX is structurally similar to methotrexate but has a greater affinity for the reduced folate carrier and exerts its effects by binding to and activating the enzyme dyhydrofolate reductase, thus depleting intracellular stores of reduced folate and interfering with DNA synthesis. ${ }^{74}$ PROPEL (Pralatrexate in Relapsed and Refractory Peripheral T-cell Lymphoma) is a prospective single-arm multicenter study in patients with relapsed or refractory aggressive PTCL. ${ }^{75}$ The study enrolled 115 patients with a variety of PTCL subtypes between August 2006 and April 2008, out of which 109 were evaluable. The treatment schedule consisted of PDX given at $30 \mathrm{mg} / \mathrm{m}^{2}$ intravenously weekly for 6 weeks followed by 1 -week's rest in a 7-week cycle. Folic acid and vitamin B12 supplementation was administered for all patients. Based on an independent central review, the overall response rate (ORR) for all patients was $29 \%$, with 9 patients (9\%) achieving a complete remission. Sixty-six percent of the responses occurred after cycle 1 of therapy and the median duration of response was 9.4 months. Mucositis was seen in over $70 \%$ of patients, and was grade 3 or 4 in $21 \%$. Hematologic toxicity consisted of thrombocytopenia and anemia. Other toxicities were mild and included fatigue, nausea, dyspnea, and mild abnormalities of liver function and serum electrolytes.

Other notable antimetabolites that have been studied in PTCL include gemcitabine, clofarabine, nelarabine, and forodesine. Zinzani et al used gemcitabine in 39 patients with mycoses fungoides and PTCL and achieved an overall response rate of $51 \% .{ }^{76}$ Horwitz et al presented preliminary data on clofarabine at a starting dose of $4 \mathrm{mg} / \mathrm{m}^{2}$ daily for 3

Table 4 Selected studies of novel therapies in relapsed or refractory $\mathrm{PTCL}$

\begin{tabular}{llll}
\hline Study & Agent & Patients (n) & ORR \\
\hline Mercieca $^{92}$ & Pentostatin & 145 & $34 \%$ \\
Sallah $^{93}$ & Gemcitabine & 10 & $60 \%$ \\
Enblad $^{83}$ & Alemtuzumab & 14 & $35 \%$ \\
Arkenau $^{94}$ & Gemcitabine combination & 16 & $69 \%$ \\
Dang $^{86}$ & Denileukin diftitox & 27 & $48 \%$ \\
Bartlettt $^{84}$ & Anti-CD30, iratumumab & 24 & $17 \%$ \\
Kim $^{95}$ & Alemtuzumab + DHAP & 24 & $50 \%$ \\
Zinzani $^{76}$ & Gemcitabine & 20 & $55 \%$ \\
D'Amore $^{87}$ & Anti-CD4, zanolimumab & 21 & $24 \%$ \\
Dueck $^{90}$ & Lenalidomide & 24 & $30 \%$ \\
O'Connor $^{74}$ & Pralatrexate & 115 & $29 \%$ \\
Piekarz $^{81}$ & Romidepsin & 47 & $38 \%$ \\
Coiffier $^{96}$ & Romidepsin & 131 & $30 \%$ \\
\hline Abbrevatin
\end{tabular}

Abbreviations: DHAP, dexamethasone-cytarabine-cisplatin; PTCL, peripheral T-cell lymphoma. 
consecutive days repeated every 3 weeks. Of the first eleven patients, there was only one PR and one CR lasting more than 9 months. ${ }^{77}$ Nelarabine is effective in T-ALL, however, its activity in PTCL is limited and associated with excessive neurotoxicity. ${ }^{78,79}$ Forodesine has demonstrated activity in T-ALL and cutaneous T-cell lymphoma [CTCL] and further studies in PTCL are needed. ${ }^{80}$

\section{HDAC inhibitors}

HDAC inhibitors are epigenetic agents with early clinical activity in PTCL. Two agents of this class, vorinostat and romidepsin, are currently approved for the treatment of CTCL in the USA. HDAC inhibitors are thought to exert their antitumor effect by modulating gene expression and thereby influencing cell differentiation or apoptosis. In a Phase II study of 47 patients with relapsed or refractory PTCL, romidepsin showed an ORR of $38 \%$ and the median duration of response was 8.9 months. ${ }^{81}$ The dose was $14 \mathrm{mg} / \mathrm{m}^{2}$ given on days 1,8 , and 15 of a 28-day cycle. Common toxicities were nausea, fatigue, and transient thrombocytopenia and granulocytopenia. Romidepsin was FDA approved for the treatment of relapsed or refractory PTCL in June 2011.

\section{Immunotherapy}

Alemtuzumab is a humanized monoclonal antibody against CD52, which is highly expressed on malignant T cells. ${ }^{82}$ Enblad et al studied alemtuzumab in 14 patients with advanced-stage PTCL. The ORR was 36\%, including three complete remissions lasting 2, 6, and 12 months, but there was significant myelotoxicity and opportunistic infection. ${ }^{83}$ Alemtuzumab has also been studied in combination with CHOP as the initial treatment of PTCL. Despite high CR rates, the upfront studies documented serious infectious complications. ${ }^{65,66}$

CD30, a member of the tumor necrosis factor receptor family, is expressed on malignant hematopoietic cells and plays a role in regulation of cell growth and survival. AntiCD30 monoclonal antibodies are of potential interest in PTCL that expresses CD30, notably ALCL. Bartlett et al reported a Phase I multidose study of the chimeric SGN-30 monoclonal antibody in 24 patients with relapsed and refractory Hodgkin's lymphoma and CD30+ ALCL. ${ }^{84}$ Treatment was well tolerated and, although there were no responses in Hodgkin's lymphoma, the PR rate was $17 \%$ in ALCL. SGN-35 is a drug-antibody conjugate in which SGN-30 is linked to auristatin. In a Phase I trial including 36 patients with Hodgkin's lymphoma and three with other CD30+NHL, no dose-limiting toxicity was identified. The ORR for patients treated at a dose of at least $1.2 \mathrm{mg} / \mathrm{kg}$ was $45 \%$, including five $(23 \%)$ CRs. ${ }^{85}$

Denileukin diftitox is a recombinant fusion protein containing the interleukin 2 (IL-2) protein and a truncated portion of the diphtheria toxin, which targets cells expressing the IL-2 receptor. It is approved for the treatment of CTCL and also appears to have activity against PTCL. Dang et al reported on 27 patients with relapsed or refractory PTCL. Six patients (22\%) achieved a CR and seven (26\%) showed a PR. The median PFS was 6 months after a median of 2.5 prior therapies. ${ }^{86}$

Other antibodies being studied in PTCL include zanolimumab, directed at CD4+ cells, and siplizumab, directed at CD2+ cells. ${ }^{87,88}$

\section{Other investigational therapies}

Lenalidomide is an immunomodulatory agent that has demonstrated clinical efficacy in several hematologic malignancies. Its exact mechanism of action is unknown but is hypothesized to include direct cytotoxicity to tumor cells, immunomodulatory responses such as cytokine modulation, enhanced NK- and T-cell function, and anti-angiogenesis effects. ${ }^{89}$ Dueck et al have reported the interim analysis of a Phase II study of 24 patients with PTCL. ${ }^{90}$ The overall response rate was $7 / 23(30 \%)$ evaluable patients. All were partial responses and two patients had stable disease for $\geq 5$ cycles. The most common grade- 4 adverse event was thrombocytopenia (33\%) and the most common grade-3 adverse events were neutropenia (21\%), febrile neutropenia (17\%), and pain not otherwise specified (17\%).

Bortezomib, the first proteasome inhibitor to enter clinical trials, was initially approved by the FDA for the treatment of relapsed and refractory multiple myeloma. Clinical trials are exploring the activity of bortezomib in PTCL. Lee et al conducted a Phase I trial of CHOP and bortezomib in 13 previously untreated patients with PTCL or NK/T-NHL. ${ }^{91}$ Although they did not meet the maximum tolerated dose of bortezomib at $1.6 \mathrm{mg} / \mathrm{m}^{2}$ on a weekly schedule, the CR was $61.5 \%$. They concluded that the regimen was well tolerated and active.

\section{Conclusion}

The treatment of patients with PTCL remains challenging. The rarity of PTCL and lack of randomized trials are the principal reasons for a lack of consensus regarding optimal therapy for T- and NK-cell neoplasms. Current recommendations are based on small case series, Phase II trials, and expert opinions. In the frontline setting, there is no 
accepted standard and CHOP or CHOP-like chemotherapy is frequently used. The addition of etoposide to CHOP in younger patients appears to improve response rates. ASCT can improve long-term disease control and should be applied either during the first CR/PR, or as part of upfront treatment for most PTCL subtypes, excluding ALK-positive ALCL. The role of allogeneic stem cell transplantation is still under investigation. Unfortunately, most patients relapse after initial induction chemotherapy and new and more effective agents are desperately needed. In the relapsed, refractory setting, pralatrexate, a folate analog, and romidepsin, a histone deacetylase inhibitor, are the only FDA-approved therapies for second-line therapy in PTCL. A number of other novel agents show preliminary activity and a large development pipeline exists. Patients should be entered on clinical trials whenever possible. To date, treatment approaches have been similar among the PTCL subtypes; however, given the underlying biologic heterogeneity, subtype-specific therapies may be more optimal. This approach has been utilized in the treatment of NKTCL and ATLL, where radiotherapy and AZT/IFN should be considered, respectively.

\section{Disclosure}

The authors report no conflicts of interest in this work.

\section{References}

1. Swerdlow S, Campo E, Harris N, et al. World Health Organization Classification of Tumours of Haematopoietic and Lymphoid tissues. 4th ed. Lyon: International Agency for Research on Cancer; 2008.

2. Jaffe ES, Harris NL, Stein H, Vardiman JW, editors. World Health Organization Classification of Tumours: Pathology and Genetics of Tumors of Hematopoietic and Lymphoid Tissues. Lyon: IARC Press; 2001.

3. Jaffe ES. Pathobiology of peripheral T-cell lymphomas. Hematology Am Soc Hematol Educ Program. 2006:317-322.

4. Abouyabis AN, Shenoy PJ, Lechowicz MJ, Flowers CR. Incidence and outcomes of the peripheral T-cell lymphoma subtypes in the United States. Leuk Lymphoma. 2008;49(11):2099-2107.

5. Rudiger T, Weisenburger DD, Anderson JR, et al. Peripheral T-cell lymphoma (excluding anaplastic large-cell lymphoma): results from the Non-Hodgkins Lymphoma Classification Project. Ann Oncol. 2002;13(1):140-149.

6. Vose J, Armitage J, Weisenburger D. International T-Cell Lymphoma Project. International peripheral T-cell and natural killer/T-cell lymphoma study: pathology findings and clinical outcomes. J Clin Oncol. 2008;26(25):4124-4130.

7. ten Berge RL, de Bruin PC, Oudejans JJ, et al. ALK-negative anaplastic large-cell lymphoma demonstrates similar poor prognosis to peripheral T-cell lymphoma, unspecified. Histopathology. 2003;43(5): $462-469$.

8. Savage KJ, Harris NL, Vose JM, et al. ALK-anaplastic large-cell lymphoma is clinically and immunophenotypically different from both ALK+ ALCL and peripheral T-cell lymphoma, not otherwise specified: report from the International Peripheral T-cell Lymphoma Project. Blood. 2008;111(12):5496-5504.

9. Nelson M, Horsman DE, Weisenburger DD, et al. Cytogenetic abnormalities and clinical correlations in peripheral T-cell lymphoma. Br J Haematol. 2008;141(4):461-469.
10. Zettle A, Rudiger T, Konrad MA, et al. Genomic profiling of peripheral T-cell lymphoma, unspecified, and anaplastic large T-cell lymphoma delineates novel recurrent chromosomal alterations. Am J Pathol. 2004;164(5):1837-1848.

11. Martinez-Delgado B, Cuadros M, Honrado E, et al. Differential expression of NF-kappa B pathway genes among peripheral T-cell lymphomas. Leukemia. 2005;19(12):2254-2263.

12. Piccaluga PP, Agostinelli C, Zinzani PL, et al. Expression of plateletderived growth factor receptor alpha in peripheral T-cell lymphoma not otherwise specified. Lancet Oncol. 2005;6(6):440.

13. Streubel B, Vinatzer U, Willheim M, Raderer M, Chott A. Novel t (5;9) (q33;q22) fuses ITK to SYK in unspecified peripheral T-cell lymphoma. Leukemia. 2006;20(2):313-318.

14. Piva R, Agnelli L, Pellegrino E, et al. Gene expression profiling uncovers molecular classifiers for the recognition of anaplastic largecell lymphoma within peripheral T-cell neoplasms. J Clin Oncol. 2010;28(9):1583-1590.

15. De Leval L, Gaulard P. Pathobiology and molecular profiling of peripheral T-cell lymphomas. Hematology Am Soc Hematol Educ Program. 2008:272-279.

16. Gallamini A, Stelitano C, Calvi R, et al. Peripheral T-cell lymphoma unspecified (PTCL-U): a new prognostic model from a retrospective multicentric clinical study. Blood. 2004;103(7):2474-2479.

17. De Leval L, Gisselbrecht C, Gaulard P. Advances in the understanding and management of angioimmunoblastic T-cell lymphoma. Br J Haematol. 2010;148(5):673-689.

18. Iqbal J, Weisenburger DD, Greiner TC, et al. Molecular signatures to improve diagnosis in peripheral T-cell lymphoma and prognostication in angioimmunoblastic T-cell lymphoma. Blood. 2010; 115(5):1026-1036.

19. Pautier P, Devidas A, Delmer A, et al. Angioimmunoblastic-like T-cell non Hodgkin's lymphoma: outcome after chemotherapy in 33 patients and review of the literature. Leuk Lymphoma. 1999;32(5-6): 545-552.

20. Advani R, Horwitz S, Zelenetz A, Horning SJ. Angioimmunoblastic T-cell lymphoma: treatment experience with cyclosporine. Leuk Lymphoma. 2007;48(3):521-525.

21. Gerlando Q, Babera V, Ammatuna E, Franco V, Florena AM, Mariani G. Successful treatment of angioimmunoblastic lymphadenopathy with dysproteinemia-type T-cell lymphoma combined with methotrexate and prednisone. Haematologica. 2000;85(8):880-881.

22. Dogan A, Ngu LS, Ng SH, Cervi PL. Pathology and clinical features of angioimmunoblastic T-cell lymphoma after successful treatment with thalidomide. Leukemia. 2005;19(5):873-875.

23. Joly B, Frankel V, Belhadj K, et al. Rituximab in combination with CHOP regimen in T-cell angioimmunoblastic lymphoma (AITL-TL) rich in large B cells. Favourable results in four patients [Abstract]. J Clin Oncol. 2004;22(14S):6694.

24. Amengual JE, Raphael BG. Sustained, durable responses with alemtuzumab in refractory angioimmunoblastic T-cell lymphoma. Leuk Lymphoma. 2010;51(7):1347-1350.

25. Kyriakou C, Canals C, Goldstone A, et al. High-Dose Therapy and Autologous Stem-Cell Transplantation in Angioimmunoblastic Lymphoma: Complete Remission at Transplantation Is the Major Determinant of Outcome- Lymphoma Working Party of the European Group for Blood and Marrow Transplantation. J Clin Oncol. 2008; 26(2):218-224.

26. Kyriakou C, Canals CM, Finke J, et al. Allogeneic stem cell transplantation is able to induce long-term remissions in angioimmunoblastic $\mathrm{T}$ cell lymphoma: a retrospective study from the lymphoma working party of the European group for blood and marrow transplantation. J Clin Oncol. 2009;27(24):3951-3958.

27. Stein H, Mason DY, Gerdes J, et al. The expression of the Hodgkin's disease associated antigen $\mathrm{Ki}-1$ in reactive and neoplastic lymphoid tissue: evidence that Reed-Sternberg cells and histiocytic malignancies are derived from activated lymphoid cells. Blood. 1985;66(4): 848-858.

28. Rimokh R, Maguad JP, Berger F, et al. A translocation involving a specific breakpoint (q35) on chromosome 5 is characteristic of anaplastic large cell lymphoma ('Ki-1 lymphoma'). Br J Haematol. 1989; 71(1):31-36. 
29. Amin HM, Lai R. Pathobiology of ALK+ anaplastic large-cell lymphoma. Blood. 2007;110(7):2259-2267.

30. Bitter MA, Franklin WA, Larson RA, et al. Morphology of Ki-1 (CD30)-positive non-Hodgkin's lymphoma is correlated with clinical features and the presence of a unique chromosomal abnormality, $\mathrm{t}(2 ; 5)$ (p23;q35). Am J Surg Pathol. 1990;14(4):305-316.

31. Savage KJ, Harris NL, Vose JM, et al. ALK-anaplastic large-cell lymphoma is clinically and immunophenotypically different from both ALK+ALCL and peripheral T-cell lymphoma, not otherwise specified: report from the International Peripheral T-Cell Lymphoma Project. Blood. 2008;111(12):5496-5504.

32. A clinical evaluation of the International Lymphoma Study Group classification of non-Hodgkin's lymphoma. The Non-Hodgkin's Lymphoma Classification Project. Blood. 1997;89(11):3909-3918.

33. Falini B, Pileri S, Zinzani PL, et al. ALK+ lymphoma: clinicopathologic findings and outcome. Blood. 1999;93(8):2697-2706.

34. Jagasia M, Morgan D, Goodman S, et al. Histology impacts the outcome of peripheral T-cell lymphomas after high dose chemotherapy and stem cell transplant. Leuk Lymphoma. 2004;45(11):2261-2267.

35. Blystad AK, Enblad G, Kvaloy S, et al. High-dose therapy with autologous stem cell transplantation in patients with peripheral $\mathrm{T}$ cell lymphomas. Bone Marrow Transplant. 2001;27(7):711-716.

36. Kwak EL, Bang Y-J, Camidge DR, et al. Anaplastic lymphoma kinase inhibition in non-small-cell-lung cancer. $N$ Engl $J$ Med. 2010;363(18):1693-1703.

37. Gambacorti-Passerini C, Messa C, Pogliani EM. Crizotinib in Anaplastic Large-Cell Lymphoma. N Engl J Med. 2011;364(8):775-776.

38. Harabuchi Y, Imai S, Wakashima J, et al. Nasal T-cell lymphoma causally associated with Epstein-Barr virus: clinicopathologic, phenotypic, and genotypic studies. Cancer. 1996;77(10):2137-2149.

39. Huang Y, de Reynies A, de Leval L, et al. Gene expression profiling identifies emerging oncogenic pathways operating in extranodal NK/T-cell lymphoma, nasal type. Blood. 2010;115(6):1226-1237.

40. Ma HH, Qian LT, Pan HF, et al. Treatment outcome of radiotherapy alone versus radiochemotherapy in early stage nasal natural killer/T-cell lymphoma. Med Oncol. 2010;27(3):798-806.

41. Jaccard A, Gachard N, Marin B, et al. Efficacy of L-asparaginase with methotrexate and dexamethasone (AspaMetDex regimen) in patients with refractory or relapsing extranodal NK/T-cell lymphoma, a phase 2 study. Blood. 2011;117(6):1834-1839.

42. Proietti FA, Carneiro-Proietti AB, Catakan-Soares BC, Murphy EL. Global epidemiology of HTLV-1 infection and associated diseases. Oncogene. 2005;24(39):6058-6068.

43. Shimoyama M. Diagnostic criteria and classification of clinical subtypes of adult t-cell leukemia-lymphoma. A report from the Lymphoma Study Group (1984-1987). Br J Haematol. 1991;79(3):428-437.

44. Sun SC, Yamaoaka S. Activation of NF-kappa B by HTLV-1 and implications for cell transformation. Oncogene. 2005;24(39):5952-5964.

45. Ramos JC, Ruiz P, Ratner L, et al. IRF-4 and c-REL expression in antiviral-resistant adult T-cell leukemia/lymphoma. Blood. 2007; 109(7):3060-3068.

46. Oshiro A, Tagawa H, Ohshima K, et al. Identification of subtype-specific genomic alterations in aggressive adult T-cell leukemia/lymphoma. Blood. 2006;107(11):4500-4507.

47. Ishitsuka $\mathrm{K}$, Tamura $\mathrm{K}$. Treatment of adult T-cell leukemia/lymphoma: past, present, and future. Eur J Haematol. 2008;80(3):185-196.

48. Tsukasaki K, Utsunomiya A, Fukuda H, et al. VCAP-AMP-VECP compared with biweekly CHOP for adult T-cell leukemia lymphoma: Japan Clinical Oncology Group Study JCOG9801. J Clin Oncol. 2007;25(34):5458-5464.

49. Gill PS, Harrington W, Kaplan MH, et al. Treatment of adult T-cell leukemia/lymphoma with a combination if interferon alpha and zidovudine. N Engl J Med. 1995;332(26):1744-1748.

50. Hermine O, Bouscary D, Gessain A, et al. Brief Report: Treatment of HTLV-1 associated adult T-cell leukemia-lymphoma with a combination of zidovudine and alpha-interferon. $N$ Engl J Med. 1995;332(26):1749-1751.
51. Hermine O, Allard I, Levy V, et al. A prospective phase II clinical trial with the use of zidqvudine and alpha interferon in the acute and lymphomatous forms of adult T-cell leukemia/lymphoma. Hematol $J$. 2002;3(6):276-282.

52. Bazarbachi A, Plumelle Y, Ramos C, et al. Meta-analysis on the use of zidovudine and interferon-alfa in adult T-cell leukemia/lymphoma showing improved survival in the leukemic subtypes. J Clin Oncol. 2010;28(27):4177-4183.

53. Phillips AA, Willim R, Savage D, et al. A multi-institutional experience of autologous stem cell transplantation in North American patients with human T-cell lymphotropic virus type-1 adult T-cell leukemia/ lymphoma suggests ineffective salvage of relapsed patients. Leuk Lymphoma. 2009;50(6):1039-1042.

54. Fukushima T, Miyazaki Y, Honda S, et al. Allogeneic hematopoietic stem cell transplantation provides sustained long-term survival for patients with adult T-cell leukemia/lymphoma. Leukemia. 2005;19(5):829-834.

55. Zettl A, deLeeuw R, Haralambieva E, Mueller-Hermelink HK. Enteropathy-type T-cell lymphoma. Am J Clin Pathol. 2007;127(5): 701-706.

56. Sieniawski M, Angamuthu N, Boyd K, et al. Evaluation of enteropathyassociated T-cell lymphoma comparing standard therapies with a novel regimen including autologous stem cell transplantation. Blood. 2010;115 (18):3664-3670.

57. Tack GJ, Verbeek WH, Al-Toma A, et al. Evaluation of Cladribine treatment in refractory celiac disease type II. World J Gastroenterol. 2011;17(4):506-513.

58. Falchook GS, Vega F, Dang NH, et al. Hepatosplenic gammadelta T-cell lymphoma: clinicopathological features and treatment. Ann Oncol. 2009;20(6):1080-1085.

59. Zelenetz AD, Abramson JS, Advani RH, et al. NCCN Clinical Practice Guidelines in Oncology: Non-Hodgkin's Lymphomas; Version 3.2011. Available from: http://www.nccn.org/. Accessed May 6, 2011.

60. Fisher RI, Gaynor ER, Dahlberg S, et al. Comparison of a standard regimen (CHOP) with three chemotherapy regimens for advanced non-Hodgkin's lymphoma. $N$ Engl J Med. 1993;328(14):1002-1006.

61. Schmitz N, Trumper L, Ziepert M, et al. Treatment and prognosis of mature T-cell and NK-cell lymphoma: an analysis of patients with T-cell lymphoma treated in studies of the German High-Grade Non-Hodgkin Lymphoma Study Group. Blood. 2010;116(18):3418-3425.

62. Simon A, Peoach M, Casassus P, et al. Upfront VIP-reinforced$\mathrm{ABVD}$ (VIP-rABVD) is not superior to $\mathrm{CHOP} / 21$ in newly diagnosed peripheral $\mathrm{T}$ cell lymphomas. Results of the randomized phase III trial GOELAMS-LTP95. Br J Haematol. 2010;151(2):159-166.

63. Sung HJ, Kim SJ, Seo HY, et al. Prospective analysis of treatment outcome and prognostic factors in patients with T-cell lymphomas treated by CEOP-B: single institutional study. $\mathrm{Br} J$ Haematol. 2006;134(1):45-53.

64. Kim JG, Sohn SK, Chae YS, et al. CHOP plus etoposide and gemcitabine (CHOP-EG) as front-line chemotherapy for patients with peripheral T-cell lymphomas. Cancer Chemother Pharmacol. 2006;58(1):35-39.

65. Kim JG, Sohn SK, Chae YS, et al. Alemtuzumab plus CHOP as frontline chemotherapy for patients with peripheral T-cell lymphomas: a phase II study. Cancer Chemother Pharmacol. 2007;60(1):129-134.

66. Gallamini A, Zaja G, Patti C, et al. Alemtuzumab (Campath-1H) and $\mathrm{CHOP}$ chemotherapy as first-line treatment of peripheral T-cell lymphoma: results of a GITL (Gruppo Italiano Terapie Innovative nei Linfomi) prospective multicenter trial. Blood. 2007;110(7): 2316-2323.

67. Takamatsu Y, Suzumiya J, Utsunomiya A, et al. THP-COP regimen for the treatment of peripheral T-cell lymphoma and adult T-cell leukemia/lymphoma: a multicenter phase II study. Eur J Haematol. 2010;84(5):391-397.

68. Kluin-Nelemans HC, van Marwijk Kooy M, Lugtenburg PJ, et al. Intensified alemtuzumab-CHOP therapy for peripheral T-cell lymphoma. Ann Oncol. 2011;22(7):1595-1600. 
69. d'Amore F, Jantunen E, Relander T. Hematopoeitic stem cell transplantation in T-cell malignancies: who, when and how? Curr Hematol Malig Rep. 2009;4(4):236-244.

70. Rodriguez J, Caballero MD, Gutierrex A, et al. High-dose chemotherapy and autologous stem cell transplantation in peripheral T-cell lymphoma: the GEL-TAMO experience. Ann Oncol. 2003;14(12):1768-1775.

71. Reimer P, Ruediger T, Geissinger E, et al. Autologous stem-cell transplantation as first-line therapy in peripheral T-cell lymphomas: results of a prospective multicenter study. J Clin Oncol. 2009;27(1):106-113.

72. Corradini P, Dodera A, Zallio F, et al. Graft versus lymphoma effect in relapsed peripheral T-cell non-Hodgkin's lymphomas after reduced intensity conditioning followed by allogeneic transplantation of hematopoietic cells. J Clin Oncol. 2004;22(11):2172-2176.

73. Le Gouill S, Milpied N, Buzyn A, et al. Graft versus lymphoma effect for aggressive T-cell lymphomas in adults: a study by the Societe Francaise de Greffe de Moelle et de Therapie Cellulaire. J Clin Oncol. 2008;26(14):2264-2271.

74. O'Connor OA, Horwitz S, Hamlin P, et al. Phase II-I-II study of two different doses and schedules of pralatrexate, a high affinity substrate for the reduced folate carrier (RFC-1), in patients with relapsed or refractory lymphoma reveals marked activity in T-cell malignancies. J Clin Oncol. 2009;27(26):4357-4364.

75. O'Connor OA, Pro B, Pinter-Brown L, et al. Pralatrexate in patients with relapsed or refractory peripheral T-cell lymphoma: Results from the pivotal PROPEL study. J Clin Oncol. 2011;29(9):1182-1189.

76. Zinzani PL, Venturini F, Stefoni V, et al. Gemcitabine as single agent in pretreated T-cell lymphoma patients: evaluation of the long-term outcome. Ann Oncol. 2010;21(4):860-863.

77. Horwitz S, Mulford D, Paul H, et al. Clofarabine is active in peripheral T-cell lymphomas: results of the phase I portion of a phase I/II study. Ann Oncol. 2008;19(Suppl 4):iv157 (abstract \#244).

78. DeAngelo DJ, Yu D, Johnson JL, et al. Nelarabine induces complete remissions in adults with relapsed or refractory T-lineage acute lymphoblastic leukemia or lymphoblastic lymphoma: Cancer and Leukemia Group B study 19 801. Blood. 2007;109(12):5136-5142.

79. Czuczman MS, Porcu P, Johnson J, et al. Results of a phase II study of 506U78 in CTCL and PTCL. Blood. 2004;104(Suppl 1):682a (abstract \#2486).

80. Gandhi V, Kilpatrick JM, Plunkett W, et al. A proof-of-principle pharmacokinetic, pharmacodynamic, and clinical study with purine nucleoside phophorylase inhibitor immucillin-H (BCX-1777, forodesine). Blood. 2005;106(13):4253-4260.

81. Piekarz RL, Frye R, Prince HM, et al. Phase II trial of romidepsin in patients with peripheral T-cell lymphoma. Blood. 2011;117(22):5827-5834.

82. Ginaldi L, De Martinis M, Matutes E, et al. Levels of expression of CD52 in normal and leukemic B and T cells: correlation with in vivo therapeutic responses to Campath-1H. Leuk Res. 1998;22(2):185-191.
83. Enblad G, Hagberg H, Erlanson M, et al. A pilot study of alemtuzumab (anti-CD52 monoclonal antibody) therapy for patients with relapsed or chemotherapy-refractory peripheral T-cell lymphomas. Blood. 2004;103(8):2920-2924.

84. Bartlett NL, Younes A, Carabasi MH, et al. A phase 1 multidose study of SGN-30 immunotherapy in patients with refractory or recurrent CD30+ hematologic malignancies. Blood. 2008;111(4):1848-1854.

85. Younes A, Forero-Torres A, Bartlett NL, et al. Objective responses in a phase I dose-escalation study of SGN-35, a novel antibody-drug conjugate (ADC) targeting CD30, in patients with relapsed or refractory Hodgkin Lymphoma. Ann Oncol 2008;19(Suppl 4):iv129-iv130. (abstract \#141).

86. Dang NH, Pro B, Hagemeister FB, et al. Phase II trial of denileukin diftitox for relapsed/refractory T-cell non-Hodgkin's lymphoma. $\mathrm{Br} J$ Haematol. 2007;136(3):439-447.

87. D'Amore F, Radford J, Relander T, et al. Phase II trial of zanolimumab (HuMax-CD4) in relapsed or refractory non-cutaneous peripheral T-cell lymphoma. Br J Haematol. 2010;150(5):565-573.

88. O’Mahoney JC, Morris JC, Moses L, et al. Phase I trial of siplizumab in CD2-positive lymphoproliferative disease. Blood. 2005;106:937a (abstract \#3353).

89. Davies F, Baz R. Lenalidomide mode of action: linking bench and clinical findings. Blood Rev. 2010;Suppl 1:S13-S19.

90. Dueck G, Chua N, Prasad A, et al. Interim report of a phase 2 clinical trial of lenalidomide for T-cell non-Hodgkin lymphoma. Cancer. 2010;116(19):4541-4548.

91. Lee J, Shuh C, Kang HJ, et al. Phase I study of proteasome inhibitor bortezomib plus CHOP in patients with advanced, aggressive T-cell or NK/T-cell lymphoma. Ann Oncol. 2008;19(12):2079-2083.

92. Mercieca J, Matutes E, Dearden C, MacLennan K, Catovsky D. The role of pentostatin in the treatment of T-cell malignancies: analysis of response rate in 145 patients according to disease subtype. J Clin Oncol. 1994;12(12):2588-2593.

93. Sallah S, Wan JY, Nguyen NP. Treatment of refractory T-cell malignancies using gemcitabine. Br J Haematol. 2001;113(1):185-187.

94. Arkenau HT, Chong G, Cunningham D, et al. Gemcitabine, cisplatin and methylprednisolone for the treatment of patients with peripheral T-cell lymphoma: the Royal Marsden Hospital experience. Haematologica. 2007;92(2):271-272.

95. Kim SJ, Kim K, Kim BS, et al. Alemtuzumab and DHAP (A-DHAP) is effective for relapsed peripheral T-cell lymphoma, unspecified: interim results of a phase II prospective study. Ann Oncol. 2009; 20(2):390-392.

96. Coiffier B, Pro B, Prince HM, et al. Final results from a pivotal, multicenter, international, open-label, phse 2 study of romidepsin in progressive or relapsed peripheral T-cell lymphoma (PTCL) following prior systemic therapy. ASH Annual Meeting Abstracts. 2010;116:114.

Journal of Blood Medicine

\section{Publish your work in this journal}

The Journal of Blood Medicine is an international, peer-reviewed, open access, online journal publishing laboratory, experimental and clinical aspects of all topics pertaining to blood based medicine including but not limited to: Transfusion Medicine; Blood collection, Donor issues, Transmittable diseases, and Blood banking logistics; Immunohematology; Artificial and alternative

blood based therapeutics; Hematology; Biotechnology/nanotechnology of blood related medicine; Legal aspects of blood medicine; Historical perspectives. The manuscript management system is completely online and includes a very quick and fair peer-review system. Visit http://www.dovepress.com/ testimonials.php to read real quotes from published authors.

\section{Dovepress}

